\title{
Family Functioning, Parenting Style, and Child Behavior in Kin Foster Care
}

\author{
Reginald C. Richardson \& James P. Gleeson
}

\begin{abstract}
Face-to-face interviews with 120 predominantly African American kin caregivers of children in the child welfare system revealed significant associations between family functioning and child behavior problems. Caregivers who reported healthier family functioning tended to report lower levels of behavior problems by the children in their care. Healthier family functioning related to roles and affective involvement were associated with lower levels of child behavior problems, but, surprisingly, less healthy family functioning related to behavior control was also associated with lower levels of child behavior problems. Caregiver ratings of their parenting styles were related to family functioning but not to their ratings of the child's behavioral functioning. Results of this study suggest several implications for child welfare practice and future research.
\end{abstract}

\section{IMPLICATIONS FOR PRACTICE}

- Child welfare practitioners should be prepared to help extended families renegotiate roles, responsibilities, and communication patterns, and express emotional support and concern for all family members in order to support the caregiver and assist in rearing children in kinship care.

- Kin-caring for children with significant behavioral problems is more likely to require professional intervention to help families adjust to and cope with the demands of care.

E or more than 25 years, a substantial portion of the children in foster care have been placed with relatives. Approximately $26 \%$ of the 408,425 children in the custody of the child welfare system in the United States are in the care of relatives (U.S. Department of Health and Human Services, 2011). While children of all racial and ethnic groups reside in kinship care, African American children are three times more likely than White children to be in the custody of the child welfare system, and after taken into custody, they are more likely to be placed with kin (Ortega, Grogan-Kaylor, Ruffolo, Clarke, \& Karb, 2010).

Long before the child welfare system "discovered" kinship care, families were caring for related children when their own parents were unable to do so, and this is particularly true for African Americans. Robert Hill's seminal works $(1972,1977,1997)$ described strong kinship bonds and informal adoption of kin as key strengths of African American families. As Danzy and Jackson (1997) wrote, the "care of a child by family members other than the biological parent is not child placement but rather family preservation.... [F]or the African-American community, the terms family preservation and kinship care are interchangeable" (p. 37). A 1994 policy statement issued by Black Administrators in Child Welfare recognized kinship care as the preferred option for children in the child welfare system who cannot live with their parents and stressed that kinship care helps children retain their cultural and family identities (Danzy \& Jackson, 1997).

While the research on the well-being of children in kinship care is growing, very little is known about the functioning of the families, the parenting styles of the kin caregivers who head these families, or the relationship that may exist among the child's functioning, family functioning, and parenting styles. This study begins to address this gap by examining the relationship between kin caregivers' perceptions of the level of problematic behavior of a sample of children in the custody of the child welfare system, parenting styles reported by these caregivers, and the caregivers' assessments of the functioning of their families. We begin with a summary of relevant research on the functioning of children in kinship care, the functioning of caregiving families, and parenting styles and practices of kinship caregivers. Next we describe the study methods and results. We end with a discussion of the study findings, limitations, and implications for future research and practice.

\section{Functioning of Children in Kin Care}

The bulk of the research on the functioning of children in kinship care has focused on children in the custody of the child welfare system, comparing caregiver ratings of those living with relatives in kin foster care to children in foster care with nonrelatives. The weight of the evidence in U.S. studies suggests that, on average, children living with kin display healthier levels of behavioral and mental health functioning compared with children in nonrelated foster care (Berrick, Barth, \& Needell, 1994; Keller et al., 2001; Rosenthal \& Curiel, 2006; Shore, Sim, LeProhn, \& Keller, 2002), but not compared to children in the general population. Two recent U.S. studies that analyzed data from the National Survey of Child and Adolescent Well- 
Being (NSCAW), a nationally representative longitudinal study of children who came into contact with the child welfare system, provide evidence that behavioral problems experienced by children living with kin are largely attributable to conditions the children experienced while living with their parents (Barth, Guo, Green, \& McRea, 2007; Rubin et al., 2008). Both studies also found that children showed greater reductions in behavioral problems over the course of their placement with kin compared with similar children who were placed in nonrelative foster care. In the samples of Barth and colleagues (2007) and Rubin and colleagues (2008), 35-40\% of the children were African American, and no racial differences were reported. While Barth et al.'s and Rubin et al.'s studies both analyzed the Child Behavior Checklist scores, in an earlier study, Berrick et al. (1994) used the Behavior Problem Index (BPI) in their comparison of 246 kinship and 354 foster family homes; $46 \%$ of the children in kinship care were African American compared with $28 \%$ of those in foster care. Results indicated lower levels of behavioral problems for children in kinship care compared with those in foster care; no differences were reported in the BPI scores between racial or ethnic groups.

More important than the comparisons between kin and nonkin care is the identification of factors associated with the healthy functioning of children. Two factors thought to contribute to healthy functioning that have received little systematic examination in kin care are parenting styles and family functioning of the caregiving family.

\section{Family Functioning of Kin and Nonkin Foster Families}

Advocates who view kin care arrangements as generally beneficial attribute much of the benefit to children remaining within their families. They claim that kin care avoids the trauma of being placed outside of the family with people unknown to them, continues family connections and contact, and reinforces children's sense of identity and self-esteem. Those critical of kin care raise questions of intergenerational dysfunction or suggest that kin care may present risk of further maltreatment because biological parents tend to have greater access to their children when they are placed with kin rather than nonkin foster parents (Clark, 1995; Dubowitz, 1994). At the core of this debate is a question about the level of functioning of the family.

Farmer and Moyers (2008) found that compared to nonrelated foster parents, kin caregivers in the United Kingdom are more likely to report conflict and frequent contact between parents of children in their care and extended family. However, these researchers did not use standardized measures of family functioning or statistically examine associations between family and child functioning. Gleeson et al. (2008) reported considerable variance in the level of family functioning reported by a predominantly African American sample of informal kinship caregivers on the Beavers Self-Report Family Instrument (SFI; Beavers, Hampson, \& Hulgus, 1990). Unhealthy family functioning, as well as a lack of family resources, and caring for a child with more serious behavior problems were associated with higher levels of caregiver stress; higher levels of caregiver stress and family dysfunction were associated with higher levels of child behavior problems. However, this study did not include children in the custody of the child welfare system. No published studies were identified that systematically examine the functioning of kin foster families using a standardized measure. However, a number of studies have demonstrated the importance of healthy family functioning among a number of populations in shaping positive outcomes for children. For example, Yoshikawa's (1994) meta-analysis of early intervention literature concluded that the most effective developmental pathway for longterm prevention of delinquency was cognitive and school competence, the quality of the parent-child relationship, and the quality of family interactions. Similarly, Garmezy (1993) argued that the factors that are protective and influence the child's resilience include, in part, family and external support. It is expected that any improvements made in the dimensions of family functioning would have a positive impact on children and would be reflected in the children's functioning.

Seaberg and Harrigan $(1997,1999)$ surveyed nonrelated licensed foster families using the Family Assessment Device (FAD; Epstein, Baldwin, \& Bishop, 1983). On average, their sample of foster families demonstrated better family functioning scores than the clinical and nonclinical samples of families used to norm the FAD. However, their study did not include kin caregivers, nor did it examine the relationship between the level of functioning of these families and the functioning of the children in their care. There were no differences by race of the foster parents on the general functioning scale or five of the six subscales. The only difference was on the affective responsiveness subscale, with White families demonstrating more favorable mean scores than African American foster families. However, both scores were more favorable than clinical and nonclinical norms (Seaberg \& Harrigan, 1999). The current study used the FAD to assess family functioning through interviews with kin foster parents and examines associations between family functioning and child behavioral functioning.

\section{Parenting Style and Child Behavior}

Parenting effectiveness researchers described a two-dimensional classification system of parenting patterns, the levels of parental demandingness and responsiveness (Baumrind, 1983, 1989; Maccoby \& Martin, 1983). Demand- 
ingness refers to parent's efforts to ensure that children are exhibiting behavioral control, demands made on children to behave in age-appropriate and socially acceptable ways, supervision of children, and disciplinary efforts. Responsiveness refers to parental warmth, supportiveness, attentiveness, and willingness to acquiesce to children's needs and demands. The research suggests that authoritative parenting, that is, high levels of demandingness and responsiveness, is optimal. Children from authoritative homes score higher on measures of competence, achievement, social development, self-esteem, and mental and emotional health than children from permissive or authoritarian homes (Lamborn, Mounts, Steinberg, \& Dornbusch, 1991; Maccoby \& Martin, 1983). Darling's (1999) review of parenting style and its correlates indicates that in the United States authoritative parenting is most common among intact, middle-class, European descent families, but that the relationship between authoritativeness and child outcomes is similar across racial and ethnic groups. Darling's review indicates that authoritative parenting predicts fewer behavior problems and overall better psychosocial outcomes for Americans of African, Asian, European, and Hispanic descent, although the dimension of demandingness is more critical to the wellbeing of males than females. A difference is noted in academic performance: Authoritative parenting is positively associated with academic performance among European and Hispanic Americans but not African or Asian Americans. Differences observed in the association of parenting style with child outcomes are likely due to differences in social context, parenting practices (vs. parenting style), or the cultural meaning of specific dimensions of parenting style (Darling \& Steinberg, 1993).

Only a few studies have systematically examined parenting styles or practices in foster care or kinship care. Barth and colleagues' (2007) analysis of NSCAW data found that $21 \%$ of their sample of children in kin and nonkin foster care were rated as experiencing low responsiveness and high punitiveness on the HOME (Home Observation for Measurement of the Environment) scale at baseline and $17 \%$ at 18 -month follow-up. There were no statistically significant differences between kin and nonkin, and racial differences were not reported. Children living with kin reported higher rates of harsh or severe parenting on the Conflict Tactics scale at 18-month follow-up compared with children living in nonkin foster homes, but the difference was not statistically significant.

Harden, Clyman, Kriebel, and Lyons (2004) compared 50 kin and 51 nonkin foster parents. Kin in this sample reported less warmth/respect, more strictness/overprotectiveness, and more parent-child conflict/anger on the Parenting Attitudes Toward Childrearing Questionnaire than nonkin foster parents. However, differences in parenting attitudes disappeared when caregiver age and marital status were entered into the analysis, suggesting that the differences in parenting attitudes were explained by the older age and single-parent status of the kin caregivers in this sample. While $96 \%$ of the kinship care sample and $80 \%$ of traditional foster parents in this study were African American, no racial differences on parenting attitudes were identified.

One longitudinal study of 6-year-old children $(N=254)$ who had been removed from their parents by 3.5 years of age found that kin caregivers were more likely to report use of physical methods to discipline the children in their care than nonrelated foster parents; however, there was no difference in reported rates of psychological aggression toward children (Litrownik, Newton, Mitchell, \& Richardson, 2003). Rates of physical and psychological aggression reported by both groups were lower than rates reported by biological parents reunified with their children and adoptive parents of these former foster children. Analysis of a subsample $(N=70)$ from the same longitudinal study found that kin were more likely than nonkin foster parents to report the use of harsh discipline. Physical punishment and harsh discipline were associated with children's aggressive responses to social problem situations but not with caregivers' ratings of children's aggressive behavior (Tripp De Robertis \& Litrownik, 2004). More than $50 \%$ of the children in kinship care in both of these studies were African American, and race was not a significant predictor of exposure to harsh discipline or children's aggressive behaviors.

The current study extends our knowledge of parenting styles in kinship care and the relationship to child functioning by examining the association between the behavioral functioning of children in kin foster care and caregiver reported levels of demandingness and responsiveness.

\section{Other Factors Associated With Parenting Styles, Family Functioning, and Child Behavior}

It is reasonable to believe that a number of unique characteristics of families involved in kinship care could have an impact on parenting styles and family functioning. Comparisons of kinship care and foster care generally report older caregiver age, more children living in the home, greater likelihood of single-parent-headed households, longer length of stays for children living in the home, and lower incomes among kinship care families (Berrick et al., 1994). In addition, all foster families must be licensed as foster parents, but this is not true for kin caregivers. However, only those who are licensed receive the full foster care payment. Kin who are not licensed generally receive a considerably lower level of financial support and may receive less training than kin in homes that are licensed. Also, families willing to care for kin may experience more people moving in and out of their household compared with other families, and these family transitions may impact overall family functioning as well as parenting and child behavioral functioning. 
Also, a number of studies suggest that children's ages and gender are associated with behavioral functioning. For example, older children and males tend to display higher levels of externalizing behavior problems. In the current study we control for caregiver age, income, length of time caring for the child, number of children and adults in the home, number of family transitions, caregiver foster home licensing status, as well as child age and gender, in our examination of relationships between parenting styles, family functioning, and child behavioral functioning.

\section{Purpose and Methods}

The current study examines family functioning, parenting styles, and child functioning in a cross-sectional survey of a purposive sample of 120 kin care providers of children in the custody of the child welfare system in a large U.S. city. We address one central research question: Do parenting styles (demandingness and responsiveness) and family functioning reported by kin caregivers predict their ratings of child behavior, controlling for caregiver age, total household income, length of time caring for the child, number of children and adults in the home, number of family transitions, caregiver foster home licensing status, and the focus child's age and gender?

\section{Sample}

Kin caregivers were eligible for this study if they had been providing at least 18 months of care for a relative's child between the ages of 11 and 17 years, who was a ward of the state's child welfare system. Recruitment of participants for this study consisted of a multimethod approach in collaboration with 12 private child welfare agencies. The principal investigator explained the purpose and details of the study, stressing the voluntary nature of participation, and scheduled interviews with caregivers who expressed interest in response to flyers, letters of invitation, or presentations by the principal investigator. Interviews were preceded by an informed consent process. Only the primary caregiver in each kin foster family was interviewed. The families determined who they considered to be the primary caregiver. Interviews were conducted in the homes of kin caregivers, except in two instances where the caregivers preferred to be interviewed in restaurants. Kin caregivers received $\$ 20$ for their participation in the interview.

\section{Instrumentation}

The questionnaire used to guide the interviews included demographic questions and measures of parenting style, family functioning, and the level of the child's problematic behavior.

Parenting style was measured using two 15 -item scales developed to determine the levels of parental demandingness and responsiveness. The measure was developed by
Paulson (1994) and is consistent with the conceptualizations of Baumrind $(1983,1989)$ and Maccoby and Martin (1983). Caregivers rated statements about their parenting on a 5-point Likert scale. Total scores for parental demandingness and responsiveness are obtained by summing and then calculating the mean for all items within the respective scales. Higher scores indicate higher levels of demandingness or responsiveness (Paulson, 1994).

Reliability and validity testing of the original demandingness and responsiveness scales were conducted in three waves, with adolescents and their parents in the Southeast and from rural and suburban Midwest communities (Paulson \& Caldwell, 1994). The Cronbach's a coefficients generated in prior studies ranged from .71 to .79 for the demandingness scale and .74 to .78 for the responsiveness scale, suggesting good internal consistency reliability. The dimensions of demandingness and responsiveness emerged as two distinct factors in a confirmatory factor analysis, and further analysis verified construct and criterion validity of the measures (Paulson, 1994). The Cronbach's a's computed for this sample were .65 and .75 , respectively. These scales were used in this study because they have been used with diverse populations and have demonstrated positive associations with child behavioral functioning across racial and cultural groups (Darling, 1999).

Family functioning was measured by the FAD (Epstein et al., 1983). The FAD is a 60 -item questionnaire designed to measure general family functioning and six dimensions: problem solving, communication, roles, affective responsiveness, affective involvement, and behavior control. Respondents rate each item on a 4-point scale. Ratings are summed and the mean is calculated to compute subscale scores, ranging from 1 to 4 , with lower scores indicating healthier functioning.

The FAD was selected for this study because it is the same measure used by Seaberg and Harrigan $(1997,1999)$ to assess the functioning of licensed African American and European American foster families, and it had reportedly good internal consistency reliability (Cronbach's a coefficients ranging from .72 to .92), as well as good face, concurrent, and predictive validity (Epstein et al., 1983; Miller, Epstein, Bishop, \& Keitner, 1985). Cronbach's a's computed for the subscales in this study were acceptable, but somewhat lower than reported by Epstein et al.: general family functioning (.76), problem solving (.69), communication (.63), roles (.60), affective responsiveness (.58), affective involvement (.61), and behavior control (.82). We used the general family functioning subscale score and in separate analyses examined associations of each of the FAD subscales with child behavioral functioning.

Child behavior problems were measured using the BPI (Zill \& Peterson, 1989), a standardized instrument that measures the frequency and range of several childhood behaviors in the last three months. The BPI was 
developed for the National Longitudinal Survey of Youth (NLSY) as a 28-item measure of childhood behaviors; the scores range from 0 to 28 , with higher scores representing higher levels of behavior problems. The BPI has high completion rates by African Americans, Hispanics, and Whites, with modest racial and ethnic variations in scores. The instrument was chosen because of its previous use in a large kin care study (Berrick et al., 1994). The BPI has been widely used in a number of NLSYs since 1981. According to the creators of this measure (Zill \& Peterson, 1989), the BPI was normed on more than 3,500 boys and girls ages 14 to 15 years, including low-income and African American and Hispanic children, has good reliability (Cronbach's $\alpha=.90$; test-retest reliability $=.63$ ) and good face and construct validity. The Cronbach's $\alpha$ computed for this sample was .93 .

Although the BPI has six subscales, which include antisocial, anxious/depressed, headstrong, hyperactive, immature/dependent, and peer conflict/social withdrawal behaviors, the current study used only the total problem score. We did this because Spencer, Fitch, Grogan-Kaylor, and McBeath's (2005) analysis of a subsample of the NLSY found that BPI factor structures were valid for White but not African American or Hispanic youth. Therefore there is some concern that the subscales of the BPI may not be valid for the mostly African American sample in this study. For the purposes of this study, the BPI total score is used as an indicator of each caregiver's overall perception of the level of their child's behavior problems in order to determine if this perceived level of behavioral functioning is associated with the caregiver's perception of their parenting style and their family's functioning.

\section{Data Analysis}

Data were analyzed at the univariate and multivariate levels. The characteristics of the sample and the univariate descriptions of family functioning, parenting styles, and child behavioral functioning scores are presented first. Then three ordinary least squares (OLS) regression models are presented. The first examines whether caregiver age, total household income, length of time caring for children, number of children and adults in the home, number of family transitions, caregiver foster home licensing status, and the focus child's age and gender explain variance in the BPI scores. In Model 2, demandingness, responsiveness, and the FAD general family functioning scale explain additional variance in caregivers' ratings of child behavior, controlling all variables entered in the first model. The final model replaces the FAD general family functioning score with scores of individual subscales of the FAD that examine the six dimensions of family functioning. This final model examines whether different dimensions of family functioning explain variance in child behavioral functioning, controlling for the same variables included in the first model.

\section{Results}

The typical kin caregiver in this sample was African American (93\%), female (92\%), currently unmarried (73\%), and at least high school educated (69\%; see Table 1). They ranged in age from 25 to 80 years, with a median age of 48. Almost $44 \%$ of the caregivers were employed full time, $15 \%$ were employed part time, $30 \%$ were unemployed, and $11 \%$ were retired. Median household income was $\$ 26,936$, ranging from $\$ 5,280$ to $\$ 110,000$. Only $5 \%$ reported that public assistance was their primary source of income, and $19 \%$ stated that their primary source of income was the board payment received from the child welfare system for the care of the related children. Nearly $73 \%$ of the relative caregivers were licensed as foster parents and received foster care board payments to help them care for the children in their homes; $44 \%$ of the families experienced no transitions in the last 18 months; nearly $46 \%$ experienced one or two transitions; and about $3 \%$ experienced four transitions (i.e., whether the family moved to a new house/apartment, an adult left the house, an adult moved into the home, a child moved into the house, or a child left the house). The caregivers who made up this sample were experienced in providing care for their relative's child(ren). The length of time providing care ranged from 18 months to 15 years ( $M d n=5$ years). The total number of children living with the caregivers, including their own children, ranged from one to nine $(M d n=3)$.

The majority of the children who were the focus of the BPI were female (53\%). They ranged in age from 11 to 17 years, with half of the children older than age 12, and half younger. Nearly half of the children were living with an aunt $(48 \%), 38 \%$ with a grandparent, $8 \%$ with a cousin, $5 \%$ with and uncle, and $1 \%$ with a stepmother. Most caregivers were maternal relatives (63\%).

\section{Parenting Style}

The parenting style scores ranged from 2.67 to 4.80 on the demandingness dimension and 2.47 to 5.00 on the responsiveness dimension. The mean score for demandingness was 3.88 , and the median score was $3.87(S D=.45)$. The mean score for responsiveness was 3.94 , and the median score $4.0(S D=.49)$. The relative caregivers in this study scored quite high on both dimensions: $99 \%$ of the demandingness scores and $97 \%$ of the responsiveness scores clustered between 3.0 and 4.99. Only one caregiver scored lower than 3.0 on the demandingness scale, and two scored lower than 3.0 on the responsiveness scales. Using 3.0 as the natural midpoint to determine what scores were high or low suggests that all but three caregivers reported an authoritative parenting style, the most optimal of the styles conceptualized by Baumrind (1983) and Maccoby and Martin (1983). Therefore we used the demandingness and responsiveness scores in all subsequent analyses, rather 
than attempting to classify caregivers as authoritative, authoritarian, permissive, or neglectful.

\section{Family Functioning}

FAD scores ranged from 1 to 4 . Scale scores are the mean of scale items. Lower scale scores are indicative of healthier family functioning. Mean and median scores are presented below, along with the range and standard deviation for the general functioning scale and each subscale. While the range of scores varied widely, from optimal to very problematic, each of the mean scores is higher than the mean scores reported for foster parents in Seaberg and
Harrigan's (1997) study but lower than psychiatric sample norms reported by Kabacoff, Miller, Bishop, Epstein, and Keitner (1990), and except for the affective involvement scale, lower than the clinical cutting scores identified by (Miller et al., 1985).

The General Functioning scale assesses overall health and pathology of the family. The minimum score was 1.08 and the maximum score 3.67 , with a mean score of 1.97 and median score of $2.0(S D=.40)$. Of the caregivers, $60 \%$ rated the general functioning of their families within the normal range, and $40 \%$ rated their families with scores that placed them above the clinical cutting score of 2.0.

TABLE 1. Caregiver, Household, and Child (Focus of BPI) Characteristics

\begin{tabular}{|c|c|c|c|c|c|}
\hline Characteristics & Number & $\%$ & Characteristics & Number & $\%$ \\
\hline Caregiver race & & & Caregiver employment $^{c}$ & & \\
\hline African American & 112 & $93 \%$ & Full time & 52 & $44 \%$ \\
\hline White & 6 & $5 \%$ & Part time & 18 & $15 \%$ \\
\hline Hispanic & 2 & $2 \%$ & Not employed & 36 & $30 \%$ \\
\hline Caregiver gender & & & Retired & 13 & $11 \%$ \\
\hline Female & 110 & $92 \%$ & Length of time caregiving (in years) & & \\
\hline Male & 10 & $8 \%$ & $<5$ & 54 & $45 \%$ \\
\hline Caregiver age (in years) ${ }^{a}$ & & & $5-9$ & 42 & $35 \%$ \\
\hline $25-34$ & 11 & $9 \%$ & $10-15$ & 24 & $20 \%$ \\
\hline $35-44$ & 33 & $28 \%$ & Number of children in home & & \\
\hline $45-54$ & 41 & $34 \%$ & $<3$ & 52 & $43 \%$ \\
\hline $55-64$ & 17 & $14 \%$ & $3-5$ & 52 & $43 \%$ \\
\hline $65+$ & 17 & $14 \%$ & $6-8$ & 15 & $13 \%$ \\
\hline Caregiver marital status & & & 9 & 1 & $1 \%$ \\
\hline Married & 32 & $27 \%$ & Number of adults in home & & \\
\hline Divorced & 23 & $19 \%$ & 1 & 62 & $52 \%$ \\
\hline Separated & 15 & $13 \%$ & 2 & 37 & $31 \%$ \\
\hline Single & 33 & $28 \%$ & $3+$ & 21 & $18 \%$ \\
\hline Widowed & 17 & $14 \%$ & Number of family transitions & & \\
\hline Caregiver education completed & & & 0 & 53 & $44 \%$ \\
\hline Less than elementary & 9 & $8 \%$ & 1 & 38 & $32 \%$ \\
\hline Grade 8 & 29 & $24 \%$ & 2 & 17 & $14 \%$ \\
\hline High school/GED & 53 & $44 \%$ & 3 & 8 & $7 \%$ \\
\hline Trade school & 1 & $1 \%$ & 4 & 4 & $3 \%$ \\
\hline Associate's degree & 8 & $7 \%$ & Licensing status & & \\
\hline 4-yr college degree & 15 & $13 \%$ & Licensed & 87 & $73 \%$ \\
\hline Graduate degree & 5 & $4 \%$ & Unlicensed & 33 & $28 \%$ \\
\hline Household income ${ }^{\text {a }}$ & & & Focus child's age & & \\
\hline$<\$ 20,000$ & 33 & $29 \%$ & $11-12$ & 65 & $54 \%$ \\
\hline$\$ 20,000-39,999$ & 50 & $44 \%$ & $13-14$ & 20 & $17 \%$ \\
\hline$\$ 40,000-59,999$ & 21 & $18 \%$ & $15-16$ & 22 & $18 \%$ \\
\hline$\$ 60,000+$ & 10 & $9 \%$ & 17 & 13 & $11 \%$ \\
\hline Primary income source ${ }^{b}$ & & & Focus child's gender & & \\
\hline Wages & 52 & $44 \%$ & Female & 64 & $53 \%$ \\
\hline DCFS foster payments & 22 & $19 \%$ & Male & 56 & $47 \%$ \\
\hline
\end{tabular}

Public assistance

Note. BPI $=$ Behavior Problem Index. $N=120$ unless otherwise noted. Social Security

SSI

${ }^{\mathrm{a}}(n=114) ;{ }^{\mathrm{b}}(n=118) ;{ }^{\mathrm{c}}(n=119)$. Columns do not total $100 \%$ on some variables because of rounding error.

Pension/investments

Other 
A family's ability to problem-solve is a critical function to maintain effective family functioning. Scores for the problem-solving subscale on the FAD ranged from 1.17 to 3.0. The mean score for this subscale was 1.95 and the median score was $2.0(S D=.36)$. The clinical cutting score for the problem solving scale is 2.20 . Nearly $87 \%$ of caregivers rated their families' problem solving in the normal to optimal range, and only $13 \%$ rated their problem solving difficulties in the clinically significant range. Based on caregiver ratings, problem solving appears to be a strength of most of the families in this study.

The communication subscale measures the family's ability to effectively transmit and receive verbal messages. It also measures the degree of adequate and effective exchange of information among family members. Scores ranged from 1.22 to 3.33 , with a mean of 2.12 and a median of $2.11(S D=.36)$. The clinical cutting score for this subscale is 2.20 . Just over half $(51.7 \%)$ of the caregivers rated their families in the normal range, and nearly half (48.3\%) rated as having communication problems that were in the clinically significant range.

Role dimension scores ranged from 1.18 to 3.18 , with a mean of 2.21 and a median of $2.27(S D=.35)$. Nearly $57 \%$ of caregivers rated the role functioning of their families in the normal range, and just over $43 \%$ in the clinical range. Scores in the clinical range suggest difficulty in developing patterns of behaviors for providing resources, nurturing and supporting personal development, and maintaining and managing the family system.

The affective responsiveness subscale scores ranged from 1.0 to 3.0, with a mean of 2.09 and median score of $2.17(S D=.39)$. Of the caregivers, $64 \%$ rated their families in the normal range on affective responsiveness, and $36 \%$ rated their families above the 2.20 clinical cutting score, suggesting that their families had a difficult time with expression of appropriate affect over a range of situations.

The affective involvement subscale scores ranged from 1.29 to 3.71 , with a mean of 2.25 and a median of 2.29 $(S D=.38)$. Just fewer than $30 \%$ of caregivers rated their families in the normal range on the affective involvement scale, which assesses the degree to which family members are involved and interested in the activities of other family members. More than $70 \%$ of caregivers rated their families above the clinical cutting score of 2.10. Based on the ratings of caregivers, affective involvement is a significant problem in the majority of families in this study.

The behavior control subscale assesses how well members of the family maintain standards of behavior and appropriately control the behavior of family members. The mean score of 1.79 and median score of $1.89(S D=.41)$ were both well below the clinical cutoff of 1.90 . However, $45 \%$ of caregivers rated their families in the clinical range on this scale.

\section{Child Behavioral Functioning}

The scores on the BPI have a possible range of 0 to 28 , with higher scores indicating higher levels of behavior problems. The mean BPI score for the children in this sample was 13.12 , and the median was $12.0(S D=7.78)$. The scores ranged from 0 , indicating that the caregiver did not identify any problematic behavior, to 27 , suggesting serious behavioral disturbance. Although we are cautious in our interpretation of the BPI scores with this largely African American sample (Spencer et al., 2005), these findings are fairly consistent with a previous large kin care study where that sample's mean was reported as 13.9 (Berrick et al., 1994).

\section{Family Functioning, Demandingness, Responsiveness, and Child Behavioral Functioning}

Table 2 displays three regression models. In Model 1, BPI scores are regressed on caregiver age, total household income, length of time caring for children, number of children and adults in the home, the number of family transitions in the last 18 months, whether the home is licensed as a foster home, and the age and gender of the child who is the focus of the BPI ratings. Approximately $8-15 \%$ of the variance in the child behavioral rating scores is explained by this model $\left(R^{2}=0.153\right.$; adjusted $\left.R^{2}=0.079\right)$, with caregiver age, household income, number of family transitions, and licensing status making unique, statistically significant contributions. Whereas older caregivers and those reporting higher household income tended to rate the behavioral functioning of children in their care as healthier than younger caregivers and those reporting lower incomes, more family transitions compared to fewer, and being licensed as a foster home are associated with higher levels of behavior problems.

In Model 2 we added the parenting style dimensions of demandingness and responsiveness and the general family functioning scale score. This model increased the explained variance by nearly $9 \%\left(R^{2}=0.243\right.$; adjusted $\left.R^{2}=0.152\right)$. In this model, only family functioning and caregiver age made unique contributions to explaining variance in child behavioral functioning. Healthier family functioning and older caregiver age were associated with healthier child behavioral functioning. Household income, number of family transitions, and licensing status were not statistically significant in this model. Parenting styles displayed no unique statistically significant contributions to explaining variance in the child behavioral functioning scores.

In Model 3, the general family functioning scale score is replaced with the six individual dimensions of family functioning: problem solving, communication, roles, affective responsiveness, affective involvement, and behavior control. Compared to Model 1, this model increased 
the explained variance by $23 \%\left(R^{2}=0.382\right.$; adjusted $\left.R^{2}=0.271\right)$. Three of the six family functioning subscales demonstrated statistically significant unique contributions to the BPI scores. Specifically, less healthy family role and affective involvement scores are associated with higher levels of child behavior problems. However, contrary to expectations, less functional family behavioral control is associated with lower levels of child behavioral problems. Caregiver age remains significant in this model, and as in Model 1, being licensed as a foster home is associated with higher levels of child behavior problems. As in Model 2, the parenting style dimensions of demandingness and responsiveness were not statistically significant contributors to explaining the variance in child behavior problems.

While the parenting style dimensions of demandingness and responsiveness were not associated with child behavior problems, post hoc analyses revealed associations with some aspects of family functioning. Higher levels of demandingness were associated with healthier affective responsiveness $(r=-21, p \leq .05$, two-tailed) and behavior control ( $r=-48, p \leq .001$, two-tailed) in families. Higher levels of responsiveness were associated with healthier problem solving $(r=-48, p \leq .001$, two-tailed), communication ( $r=-46, p \leq .001$, two-tailed), role functioning ( $r=-23, p \leq .05$, two-tailed), affective responsiveness ( $r=-45, p \leq .001$, two-tailed), affective involvement
( $r=-28, p \leq .01$, two-tailed), behavior control $(r=-52$, $p \leq .001$, two-tailed), and general family functioning $(r=-36, p \leq .001$, two-tailed).

In our post hoc analyses we also examined associations among the behavior control family functioning subscale, BPI scores, demandingness, responsiveness, general family functioning, and other family functioning subscales. We did this in an attempt to better understand the unexpected and counterintuitive inverse relationship observed between behavior control and the BPI in the third regression model. We first examined the bivariate relationship between behavior control and the BPI score and found no statistically significant relationship $(r=.03$, $p=.75$, two-tailed). We then ran a series of regression models that systematically excluded Model 1 covariates, then demandingness, responsiveness, and the family functioning subscales. Interestingly, the relationship between behavior control and the BPI was statistically significant only in models that included the role functioning subscale. The strength of the explanatory contribution of the behavioral control scale further increased when affective involvement and communication subscale scores were also included in the equation. In models that included the communication and behavioral control subscale scores but excluded the role functioning subscale, behavior control was not statistically significant but communi-

TABLE 2. OLS Regression of BPI on Parenting Dimensions and Family Functioning, Controlling for Caregiver, Household, and Child Characteristics

\begin{tabular}{|c|c|c|c|}
\hline Variable & $\begin{array}{c}\text { Model } 1 \\
b(S E)\end{array}$ & $\begin{array}{c}\text { Model } 2 \\
b(S E)\end{array}$ & $\begin{array}{c}\text { Model } 3 \\
b(S E)\end{array}$ \\
\hline Caregiver age (in years) & $-0.18(08)^{*}$ & $-0.21(0.08)^{\star}$ & $-0.14(0.07)^{\star}$ \\
\hline Total household income & $-9.046 \mathrm{E}-5(0.00)^{\star}$ & $-6.673 \mathrm{E}-5(0.00)$ & $-4.107 \mathrm{E}-5(0.00)$ \\
\hline Length of time caregiving (in years) & $0.24(0.25)$ & $0.27(0.24)$ & $0.05(0.23)$ \\
\hline Number of children in home & $-0.53(0.46)$ & $-0.40(0.46)$ & $-0.48(0.43)$ \\
\hline Number of adults in home & $1.30(0.91)$ & $1.36(0.87)$ & $0.87(0.82)$ \\
\hline Number of family transitions & $1.54(0.72)^{*}$ & $1.28(0.70)$ & $1.29(0.66)$ \\
\hline Caregiver home licensed & $3.42(1.70)^{*}$ & $2.72(1.67)$ & $3.89(1.64)^{*}$ \\
\hline Focus child's age (in years) & $-0.53(0.35)$ & $-0.42(0.34)$ & $-0.37(0.32)$ \\
\hline Focus child's gender & $2.06(1.54)$ & $2.04(1.52)$ & $1.44(1.52)$ \\
\hline Demandingness & & $1.96(1.70)$ & $-0.75(1.79)$ \\
\hline Responsiveness & & $-0.25(1.65)$ & $-0.47(1.71)$ \\
\hline Family functioning (general) & & $6.38(2.09)^{*}$ & \\
\hline Problem solving & & & $2.40(2.66)$ \\
\hline Communication & & & $3.89(2.96)$ \\
\hline Roles & & & $6.97(2.67)^{\star}$ \\
\hline Affective responsiveness & & & $-1.27(2.64)$ \\
\hline Affective involvement & & & $6.24(2.21)^{*}$ \\
\hline Behavior control & & & $-8.24(2.65)^{\star}$ \\
\hline Intercept & $24.96(6.56)^{*}$ & $5.01(11.75)$ & $1.10(14.73)$ \\
\hline$R^{2}$ & $0.153^{*}$ & $0.243^{*}$ & $0.382^{*}$ \\
\hline Adjusted $R^{2}$ & $0.079^{*}$ & $0.152^{*}$ & $0.271^{*}$ \\
\hline$R^{2}$ change & & $0.089^{*}$ & $0.228^{*}$ \\
\hline
\end{tabular}

Note. BPI $=$ Behavior Problem Index. ${ }^{*} p<.05$. 
cation was. Therefore, the relationship between a family's behavior control, as measured by this subscale, and child behavioral functioning is complex and not direct; it is somehow related to other dimensions of family functioning, particularly role functioning, affective involvement, and communication.

\section{Limitations and Implications for Future Research}

There are a number of limitations that need to be considered in interpreting the results of this study. These are related to the sample and measures. First, because the sample is one of convenience, drawn from a single city, and $94 \%$ African American, it is clear that the generalizability of results is very limited. Any conclusions drawn from this study are particular to this sample and would need to be tested before being applied more broadly. In addition, the self-selected nature of the sample may have had an effect on findings related to parenting styles in particular. The fact that no associations were found between the parenting styles and child behavioral functioning may be due to the nature of the sample in this study. While all kin caregivers in 12 child welfare agencies were invited to participate, this sample includes only those who responded to the invitation. It may be that the highest functioning kin foster parents stepped forward and lower functioning ones did not. The fact that all but three of the caregivers in this sample reported parenting behaviors consistent with an authoritative parenting style suggests that subject self-selection bias may be a factor in this study. Barth et al.'s (2007) analysis of the NSCAW data, which relies on a nationally representative sample of children and families involved with the child welfare system, revealed considerably more variability, with a substantial percentage of kin caregivers rated low on responsiveness and high on punitiveness. It may also be that the difference between the results of the current study and Barth et al.'s study is at least partly due to the use of different measures. The responsiveness and demandingness scales used in this study are self-report measures, whereas Barth et al. used the HOME scale, which includes observational as well as self-report measures. Caregivers' ratings on the parenting measures in this study may have been influenced by social desirability bias.

The use of the BPI also raises concerns in this study. Spencer et al. (2005) raised concerns about the integrity of the factor structures of the BPI for African American and Hispanic children. Because the sample in this study is $94 \%$ African American, we use only the total BPI score and use this only as a measure of the caregiver's perceptions of the behavior problems displayed by the child to be examined in relationship to the same caregiver's perceptions of family functioning and their own parenting styles. It is not used to draw any comparative conclusions about the behavioral problems of children of different races or ethnicities.
The cross-sectional design of this study also limits what can be learned. For example, although associations were detected between family functioning, including its various dimensions, and child behavioral functioning, it is not possible to determine the degree to which family functioning influenced child behavior or child behavior influenced family functioning, or the degree to which the association between child behavior and family functioning represents a spurious relationship accounted for by some other unmeasured variable. In addition, all of the measures in this study relied on kin caregivers' perceptions. Therefore, findings from this study should be considered hypotheses to be explored in practice and tested in future longitudinal research with larger, representative samples of kinship caregiving families, using multiple measures of child behavior, family functioning, and parenting styles, and multiple reporters for each of these measures (e.g. multiple family members, caseworkers, teachers, etc.). This research would not only contribute to knowledge development, it also has the potential to shape interventions that support healthy functioning, effective parenting, and the functioning of children in kin caregiving families.

\section{Discussion and Implications for Practice}

Despite the limitations noted above, this study generated interesting findings with potential implications for practice. These findings provide empirical support for the relationship between kin caregivers' perceptions of family functioning and child behavioral functioning for children in the custody of the child welfare system, similar to that found by Gleeson et al. (2008) in informal kinship care. These findings support the need for child welfare practitioners to look beyond the caregiver-child dyad to that of the caregiving family system. Although further testing of this relationship is needed, it makes intuitive sense that the functioning of the family would affect and be affected by the behavior of related children in the family's care. In other research, family functioning characteristics have been found to account for $30-40 \%$ of the variance in level of antisocial behavior in children (Tolan \& McKay, 1996). The current study extends these findings by examining associations between child behavioral functioning and various dimensions of family functioning: role functioning, affective involvement, and behavior control.

It makes sense that kin caregiving families might experience more role strain and confusion than is experienced by the average family headed by biological or adoptive parents, and that this role strain and confusion would be associated with higher levels of child behavioral problems. Kin caregiving families adapt their roles in order to care for a child when the child's parents are unable to provide this care. Grandparents, aunts, uncles, and other relatives assume a primary caregiving role to the child in addition to the other normative roles, which may include 
being a parent to their own biological children, grandparent to several other children in the kinship network, spouse or partner, employee, and the like. In addition, unlike foster parents, kin caregivers are related to a parent of the child in their care and likely have a relationship history with the child's parent that may include many conflicts and/or attempts to help the parent successfully discharge their parenting role. The caregiver may have a long history of helping the parent deal with stressors and challenges that get in the way of successful parenting.

Hill $(1972,1997)$ identified role flexibility as one of the enduring strengths of African American families that is associated with strong kinship ties. It is clear from this study that caregivers' perceptions of healthy role functioning are associated with the child's healthy functioning. However, it is important to remember that the children in this study were in the custody of the child welfare system, which means that their parents experienced serious challenges caring for their children that brought them to the attention of legal authorities. Even strong extended families are challenged by parents who suffer from drug abuse, severe mental illness, or other challenges that prevent them from raising their children. And the challenges faced by these families may be quite longstanding. Qualitative research (Gibson, 2005) and practice wisdom regarding clinical issues in kinship care (Crumbley \& Little, 1997) confirm that agreeing to raise a relative's child can cause disruptions in the ways that family members (nuclear as well as extended) define their roles and relate to each other. Caregivers' ratings in this study suggest that over $43 \%$ of the families experienced clinical-level problems in role functioning.

Affective involvement is the adequacy of family members' involvement and interest in the activities of other members. Caregiver ratings of affective involvement were associated with child behavioral problems in this study. It does make sense that families with a number of members who take an interest and are involved with the children would directly affect the well-being of the children, while providing respite and support for kin caregivers as well. Without this involvement from a number of family members, the burden on caregivers is greater and involvement of adults in the lives of children may not be sufficient to compensate for lack of parent involvement or capacity. More than $70 \%$ of caregivers in this study rated the affective involvement of their families in the clinical range.

The relationship between family behavior control and child behavioral functioning is more difficult to explain, and $45 \%$ of caregivers rated the behavior control dimension of their family's functioning in the clinical range. Surprisingly, although family behavior control was not associated with child behavioral functioning at the bivariate level, less healthy behavior control was associated with lower levels of child behavior problems in multivariate analyses that included family role functioning; and the strength of the inverse relationship between behavior control and child behavioral functioning strengthened when affective involvement and communication subscale scores were also included in the model. This certainly is counterintuitive. It is also interesting that family behavior control is inversely related to demandingness and responsiveness, such that higher levels of these parenting style dimensions are associated with healthier behavior control. In fact, higher levels of responsiveness are associated with healthier general family functioning and all six dimensions of family functioning. Higher levels of demandingness are associated with healthier family functioning in affective responsiveness and behavior control. It is not clear why these parenting style dimensions are not associated with child behavior or why healthier family functioning in behavior control is associated with higher levels of child behavior problems when other dimensions of family functioning are included in the analysis. We can only speculate that examination of specific behavior management goals and the context of parenting may shed some light on these findings. Darling and Steinberg (1993) argued that differences observed in parenting styles of European American, African American, and Hispanic families may reflect the different contexts and goals that influence parenting styles as well as parenting practices. It may be that parenting in the context of kinship care arrangements may also be shaped differently by goals related to the reason for the kinship care arrangement and the extended family context. This suggests that social workers and other human service professionals should not automatically promote a one-size-fits-all approach to intervening with kin caregiving families to manage child behavior. Rather, it is important to understand families' perceptions of their contexts, roles, and specific parenting goals, and then work with families to fashion effective parenting strategies for raising relatives' children.

Kin caregivers' ratings of child behavioral problems displayed a wide range and were similar to those reported in a prior study that used the same measure (Berrick et al., 1994). It is important to remember that other research has demonstrated that the behavior problems displayed by children in kinship care often precede placement with kin and are associated with trauma experienced while living with their birth parents. Assuming care of a child with significant behavioral problems can take a toll on family functioning. Family functioning may be a result of caring for children with behavior problems as well as a contributor to the child's behavioral functioning. This suggests that kin caregiving families of children with behavioral problems are more likely to need support and professional intervention than kin care families with children with fewer behavioral problems, not only to help them manage the child's behavior but also to help the family adjust to and cope with the demands of caring for a relative's child who displays significant behavior problems. 
The results of this study suggest, and it makes intuitive sense, that child welfare practitioners should be prepared to help families renegotiate roles and responsibilities throughout the extended family to support the caregiver and assist in rearing the child in kin foster care; provide expressions of emotional support, concern, and care that all members of the family need; and ensure that communication patterns are clear, honest, and direct; and that the help provided is relevant to the family's context and goals. However, perhaps even more important than recognizing the challenges faced by kin care families, is recognizing and supporting their strengths. A substantial percentage of families in this study were rated by the kin caregiver in the normal to optimal range in many areas of family functioning. For example, $87 \%$ rated their families in the normal to optimal range on family problem solving. In addition, demandingness and responsiveness ratings suggest parenting strengths among this sample. Although these findings are based on self-reports of caregivers-an important source of information-child welfare practitioners are able to verify parenting styles and practice as well as family functioning through observation and interaction with kin caregiving families. It is essential that child welfare caseworkers identify strengths of kin caregiving families, as well as needs, to help them build on these strengths as they prepare to meet the challenges of caring for a relative's child.

\section{References}

Barth, R. P., Guo, S., Green, R. L., \& McRea, J. S. (2007). Kinship care and nonkinship foster care: Informing the new debate. In R. Haskins, F. H. Wulczyn, \& M. Webb (Eds.), Child protection: Using research to improve policy and practice (pp. 187-206). Washington, DC: Brookings Institution.

Baumrind, D. (1983). Rejoinder to Lewis's reinterpretation of parental firm control effects: Are authoritative families really harmonious? Psychological Bulletin, 94, 132-142.

Baumrind, D. (1989). Rearing competent children. In W. Damon (Ed.), Child development today and tomorrow (pp. 349-378). San Francisco, CA: Jossey-Bass.

Beavers, W. R., Hampson, R. B., \& Hulgus, Y. F. (1990). Beaver's systems model manual: 1990 edition. Dallas, TX: Southwest Family Institute.

Berrick, J., Barth, R., \& Needell, B. (1994). A comparison of kinship foster homes and foster family homes: Implications for kinship foster care or family preservation. Children and Youth Services Review, 16(1/2), 33-63.

Clark, J. (1995). Kinship foster care: An overview of research findings and policy-related issues 1995. University Park, PA: The Pennsylvania State University. Retrieved from ERIC database. (ED400061)

Crumbley, J., \& Little, R. (1997). Relatives raising children: An overview of kinship care. Washington, DC: Child Welfare League of America.

Darling, N. (1999). Parenting style and its correlates. ERIC Digest. Champaign, IL: Clearinghouse on Elementary and Early Childhood Education (EDO-PS-99-3). Retrieved from http:// ceep.crc.uiuc.edu/eecearchive/digests/1999/darlin99.pdf

Darling, N., \& Steinberg, L. (1993). Parenting style as context: An integrative model. Psychological Bulletin, 113(3), 487-496.
Danzy, J., \& Jackson, S. (1997). Family preservation and support services: A missed opportunity for kinship care. Child Welfare, 76, 31-44.

Dubowitz, H. (1994). Kinship care: Suggestions for future research. Child Welfare, 73(5), 553-564.

Epstein, N., Baldwin, L., \& Bishop, D. (1983). The McMaster Family Assessment Device. Journal of Marital Family Therapy, 9, 171-180.

Farmer, E., \& Moyers, S. (2008). Kinship care: Fostering effective family and friends placements. London, UK: Kingsley.

Garmezy, N. (1993). Children in poverty: Resilience despite risk. Psychiatry, 56, 127-136.

Gibson, P. (2005). Intergenerational parenting from the perspective of African American grandmothers. Family Relations, 54(2), 280-297.

Gleeson, J. P., Hsieh, C., Anderson, N., Seryak, C., Wesley, J., Choi, E. H.,... Robinson, J. (2008). Individual and social protective factors for children in informal kinship care: Final report. Chicago, Ill: Jane Addams College of Social Work, University of Illinois at Chicago. Retrieved from http://www.uic.edu/jaddams/college/ kincare/research/research.html

Harden, B. J., Clyman, R. B., Kriebel, D. K., \& Lyons, M. E. (2004). Kith and kin care: Parental attitudes and resources of foster and relative caregivers. Children and Youth Services Review, 26(7), 657-671.

Hill, R. B. (1972). The strengths of Black families. New York, NY: Emerson Hall.

Hill, R. B. (1977). Informal adoption among Black families. Washington, DC: National Urban League Research Department.

Hill, R. B. (1997). The strengths of African American families: Twentyfive years later. Washington, DC: R \& B.

Kabacoff, R., Miller, I., Bishop, D., Epstein, N., \& Keitner, G. (1990). A psychometric study of the McMaster Family Assessment Device in psychiatric, medical and nonclinical samples. Journal of Family Psychology, 3, 431-439.

Keller, T., Wetherbeck, K., LeProhn, N. S., Payne, V., Sim, K., \& Lamont, E. (2001). Competencies and problem behaviors of children in family foster care: Variations by kinship placement status and child race. Children and Youth Services Review, 23, 915-940.

Lamborn, S., Mounts, N., Steinberg, L., \& Dornbusch, S. (1991). Patterns of competence and adjustment among adolescents from authoritative, authoritarian, indulgent, and neglectful families. Child Development, 62, 1049-1065.

Litrownik, A. J., Newton, R., Mitchell, B. E., \& Richardson, K. (2003). Long-term follow-up of young children placed in foster care: Subsequent placements and exposure to family violence. Journal of Family Violence, 18(1), 19-28.

Maccoby, E., \& Martin, J. (1983). Socialization in context of the family: Parent-child interaction. In E. M. Hetherington (Ed.), P. H. Mussen (Series Ed.), Handbook of child psychology: Vol. 4. Socialization, personality, and social development (pp. 1-101). New York, NY: Wiley.

Miller, I. W., Epstein, N. B., Bishop, D. S., \& Keitner, G. I. (1985). The McMaster Family Assessment Device: Reliability and validity. Journal of Marital and Family Therapy, 11(4), 345-356.

Ortega, R. T., Grogan-Kaylor, A., Ruffolo, M., Clarke, J., \& Karb, R. (2010). Racial and ethnic diversity in the initial child welfare experience. In M. B. Webb, K. Dowd, B. J. Harden, J. Landsverk, \& M. F. Testa (Eds.), Child welfare \& child wellbeing: New perspectives from the National Survey of Child and Adolescent Well-Being (pp. 187-206). New York, NY: Oxford University Press.

Paulson, S. (1994). Relations of parenting style and parental involvement with ninth-grade students' achievement. Journal of Early Adolescence, 14(2), 250-267. 
Paulson, S., \& Caldwell, C. (1994, February). Construction and validation of 3 measures of parenting. Poster session presented at the Society for Research on Adolescence, San Diego, CA.

Rosenthal, J. A., \& Curiel, H. F. (2006). Modeling behavioral problems of children in the child welfare system: Caregiver, youth, and teacher perceptions. Children and Youth Services Review, 28, 1391-1408.

Rubin, D. M., Downes, K. J., O’Reilly, A. L. R., Mekonnen, R., Luan, X., \& Localio, R. (2008). Impact of kinship care on behavioral well-being for children in out-of-home care. Archives of Pediatrics \& Adolescent Medicine, 162(6), 550-556.

Seaberg, J. R., \& Harrigan, M. P. (1997). Family functioning in foster care. Families in Society: The Journal of Contemporary Human Services, 78(5), 463-470. doi:10.1606/1044-3894.815.

Seaberg, J. R., \& Harrigan, M. P. (1999). Foster families' functioning, experiences and views: Variations by race. Children and Youth Services Review, 21(1), 31-55.

Shore, N., Sim, K. E., LeProhn, N. S., \& Keller, T. E. (2002). Foster parent and teacher assessments of youth in kinship care and non-kinship foster care placements: Are behaviors perceived differently across settings? Children and Youth Services Review, 24(1/2), 109-134.

Spencer, M. S., Fitch, D., Grogan-Kaylor, A., \& McBeath, B. (2005). The equivalence of the Behavior Problem Index across U.S. ethnic groups. Journal of Cross-Cultural Psychology, 36(5), 573-589.

Tolan, T., \& McKay, M. (1996). Preventing serious antisocial behavior in inner-city children. An empirically based family intervention program. Family Relations, 45, 148-155.

Tripp De Robertis, M., \& Litrownik, A. J. (2004). The experience of foster care: Relationship between foster parent disciplinary approaches and aggression in a sample of young foster children. Child Maltreatment, 9(1), 92-102.
U.S. Department of Health and Human Services [Administration for Children and Families, Administration on Children, Youth and Families, Children's Bureau]. (2011). Adoption and Foster Care Reporting and Analysis System (AFCARS) Preliminary Estimates FY 2010 estimates as of July 2011. Retrieved from www.acf.hhs.gov/programs/cb

Yoshikawa, H. (1994). Prevention as cumulative protection: Effects of early family support and education on chronic delinquency and its risks. Psychological Bulletin, 115(1), 28-54.

Zill, N., \& Peterson, J. (1989). National Longitudinal Survey of Youth child handbook. Columbus: Ohio Center for Human Resources Research.

Reginald C. Richardson, PhD, LCSW, vice president for Evaluation and Clinical Services, The Family Institute at Northwestern University. James P. Gleeson, PhD, ACSW, associate professor, University of Illinois at Chicago. Correspondence: RRichardson@family-institute.org; 618 Library Place, Evanston, IL 60201

Authors' note. This research was supported by a fellowship from the Administration on Children, Youth and Families (90CA1673) and grant \#013776 from the Children and Family Research Center, University of Illinois at Urbana-Champaign, awarded to the first author.

Manuscript received: July 21, 2010

Revised: February 9, 2011

Accepted: February 14, 2011

Disposition editor: William E. Powell

\section{New Voices at the Civic Table}

\section{How six human service organizations are supporting the civic engagement of community members}

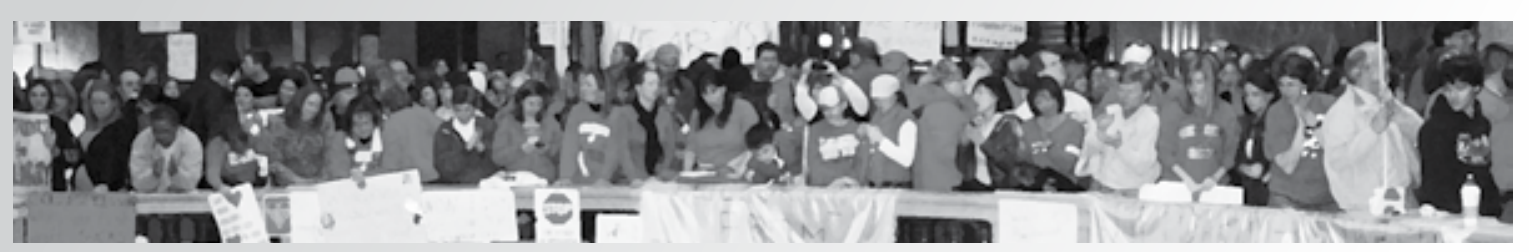

Examining the efforts, outcomes, and future plans of six nonprofit organizations that utilized funding through the Alliance for Children and Families' civic engagement program, this report provides background information for discussions about the meaning of civic engagement, ways to integrate

it into existing models of service delivery, and tools and infrastructure for sustaining such efforts.

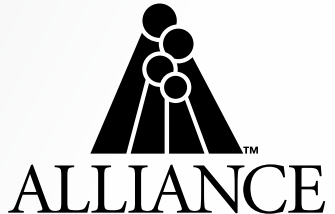

for Children \& Families

INTELlECTUAL CAPITAL DIVISION 